\title{
Characterizing the Permeability and Methane Release with the Treatment of Pressure-relief Mining: Intensive Field Measurements
}

\section{Cun Zhang}

China University of Mining and Technology (Beijing)

\section{Qingsheng Bai}

TU Bergakademie Freiberg

\section{Ziyu Song}

China University of Mining and Technology (Beijing)

\section{Yang Luo}

Huaibei Mining Group

Jianhang Chen ( $\nabla$ jianhang314@163.com )

China University of Mining and Technology (Beijing) https://orcid.org/0000-0001-8673-3077

\section{Research}

Keywords: pressure-relief mining, whole evolution, permeability coefficient, gas pressure, intensive filed measurements

Posted Date: October 21st, 2020

DOl: https://doi.org/10.21203/rs.3.rs-93214/v1

License: (c) (i) This work is licensed under a Creative Commons Attribution 4.0 International License. Read Full License 


\section{Characterizing the permeability and methane release with the treatment of} pressure-relief mining: intensive field measurements

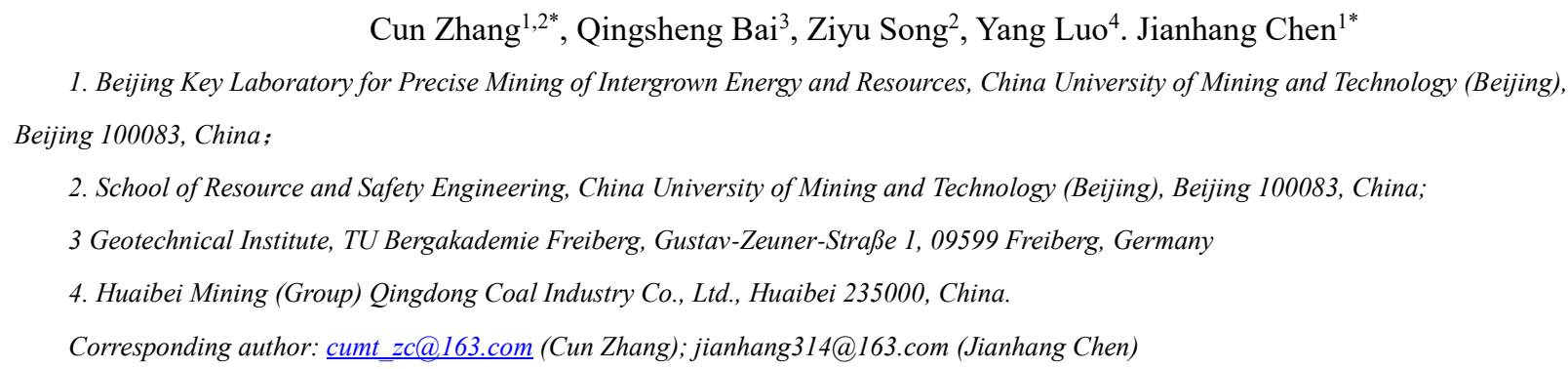

Abstract: Characterizing the permeability evolution and methane release is of great significance for the safe mining of the high gas outburst seams, as well as coal and gas simultaneous extraction. Theoretical analysis, laboratory testing, and numerical simulation are widely used methods to characterize the permeability and methane release with the treatment of pressure-relief mining. However, these methods cannot fully reflect the complexity of filed practice. In this study, we report the effectiveness of protective coal seam (PCS) mining and the pressure-relief area in the protected coal seam (PDCS) based on detailed and integrated field measurements in a Chinese coal mine. To the best of our knowledge, it is the first time to measure the permeability coefficient and gas pressure evolution in the PDCS during the PCS longwall mining. The evolution of the permeability coefficient in the pressure-relief area during PCS mining can be divided into four stages: slowly decreasing, sharply increasing, gradually decreasing, and basically stable. The maximum permeability coefficient is 322 times of the initial value and finally stabilized at 100 times after the goaf compacted. The gas pressure evolution in the PDCS indicates that the strike pressure relief angle is $52.2^{\circ}$ at the active longwall face zone, and $59.3^{\circ}$ at the installation roadway side. The tendency pressure relief angles at the lower and upper sides of the longwall panel are $75^{\circ}$ and $78.9^{\circ}$, respectively. The residual gas content and gas pressure of the PDCS in the pressure-relief area are reduced to less than $6 \mathrm{~m}^{3} / \mathrm{t}$ and within $0.4 \mathrm{MPa}$, respectively. The field measurements show that pressure-relief mining can prevent coal and gas outbursts in PDCSs. The field observations in this paper can serve as benchmark evidence for theoretical analysis and numerical simulations, and also provide insights into realizing safety mining in similar conditions.

Keywords: pressure-relief mining; whole evolution; permeability coefficient; gas pressure; intensive filed measurements

\section{Highlights:}

1. The effectiveness of protective coal seam mining and the pressure-relief area in the protected coal seam were evaluated by detailed and whole mining process field measurements in a Chinese coal mine 
2. It is the first time to measure the permeability coefficient and gas pressure evolution in the protected coal seam during the protective coal seam longwall mining.

3. The field observations in this paper can serve as benchmark evidence for theoretical analysis and numerical simulations

\section{Introduction}

Pressure-relief mining combined with three-dimensional gas drainage technology has been widely used to remove gas and coal outbursts and other dynamic disasters in China (Wang et al., 2010; Zhang et al., 2015a; Zhao et al., 2020). Many experts have investigated the pressure-relief mining of protective coal seams (PCSs) and have obtained fruitful results. A theoretical and technical system for pressure-relief gas extraction during PCS mining has been established (Sang et al., 2010; Zhou et al., 2016; Yuan, 2008). Understanding the permeability evolution and gas migration path in the protected coal seam (PDCS) is fundamental for the drainage of pressure-relief gas and the safe mining of the PCS. At present, numerical simulations and field observations are the main approaches to characterize the evolution of permeability and gas migration paths in surrounding rock mass.

The slug method is commonly used to assess the permeability of surrounding rocks and the characteristics of fracture development, especially in saturated coal seams (Koenig and Schraufnagel, 1987; Shu et al., 1995). Moreover, pumping and flow meter tests are also widely employed to evaluate the permeability of overlying rocks (Baptiste and Chapuis, 2015; Barrash et al., 2006). Three geophysical approaches (the flow meter test, color television observation, and the transient electromagnetic method) have been employed to detect fracture development in overlying strata (Sun et al., 2013), in which color television is considered the best one. Based on numerical simulations, Yuan et al. (2013) found that an annular fracture system is created in the roof after longwall mining, which is the primary gathering space for pressure-relief gas. He also proposed a scheme for gob gas drainage. Using physical modeling and the slug method, Zhang and Wang (2014) demonstrated the development of induced fractures in overlying strata. Wang et al. (2014) studied the influence of mining-induced stress on the permeability of the fracture zone. However, field measurements are usually executed after longwall mining; thus cannot predict the whole evolution of permeability in the surrounding rock mass, which is essential for the predesign of gas drainage.

The relationship between the stress and permeability in the disturbed zones (i.e., bending zone, fractured zone, and caved zone) has been summarized by laboratory tests in several studies (Esterhuizen and Karacan, 2005; 2007; Whittles et al., 2006; Zhang et al., 2018; Zhang \& Zhang., 2019), making it possible to simulate the permeability changes during mining and to evaluate the effectiveness of gas extraction. As shown in Fig.1, considering disturbed zone-dependent permeability models, people could well simulate the permeability change of PDCS during longwall retreating. The 
permeability calculation results can be imported into seepage calculation software for seepage calculation. This method provide a promising way to evaluate the effectiveness of pressure relief and permeability enhancement in the PDCS ( Rutqvist, 2011; Whittles et al., 2006; Zhang et al., 2019; Zhang et al., 2018; Guo et al., 2020). Si et al. (2015) employed FLAC3D to obtain the stress distributions during thick coal seams mining, and the stress data is then used in ECLIPSE300 to study the gas migration. However, the numerical results are poorly verified by field applications, doubting the reliability of the simulations.

In this study, we performed intensive field measurements to characterize the permeability enhancement and the associated pressure relief regionsin the PDCS during longwall retreating in the above PCS. Different from previous studies, which usually test these parameters after the PCS mining, we continually monitor the parameters mentioned above, enabling us to summarize the whole evolution of the permeability and the associated pressure-relief effectiveness during the PCS minging. Five groups of testing boreholes are arranged in PDCS to monitor the gas pressure, gas content, and permeability coefficient. The gas pressure was measured by the active pressure measurement (APM) method; the gas content was measured by the high-pressure adsorption (HPA) method; and the permeability coefficient was measured by the radial flow permeability (RFP) method. To the best our knowledge, it is the first time to investigate the permeability and gas pressure evolution of the PDCS during the PCS mining process. Moreover, regional measurements, instead of point measurements, were carried out in this work; thus, spatio-temporal evolutions of these parameters can be characterized. The outputs in this study provide fundamental insights into how permeability and gas pressure evolution of PDCS during the PCS mining process. The results can also serve as benchmarking evidence for field-scale pressure-relief mining numerical simulation and lab-scale permeability tests

\section{Engineering background}

The coal seams $7^{\#}$ and $8^{\#}$ in the Huaibei mining area, Anhui province, are outburst tendency. The $7^{\#}$ coal seam was mined as the upper PCS to prevent coal and gas outbursts in the $8^{\#}$ coal seam. The average thickness of the $7^{\#}$ coal seam is $2.0 \mathrm{~m}$ with a $527 \mathrm{~m}$ burial depth. The $8^{\#}$ coal seam has an average thickness of $8.0 \mathrm{~m}$ and is located below the $7^{\#}$ coal seam, at an average distance of $24.5 \mathrm{~m}$. The relative position of the coal seam and the lithology of the roof and floor are shown in Fig. 2. Field measurements show that the average and maximum coal gas pressure of the $7^{\#}$ coal seam are 0.8 $\mathrm{MPa}$ and $1.70 \mathrm{MPa}$, respectively, and the average gas content is $8.78 \mathrm{~m}^{3} / \mathrm{t}$. The average gas content is $8.56 \mathrm{~m}^{3} / \mathrm{t}$, and the average and the maximum gas pressure of the $8^{\#}$ coal seam are $1.1 \mathrm{MPa}$ and $1.51 \mathrm{MPa}$, respectively. The length of the first longwall face in PCS is $190 \mathrm{~m}$, and the advancing length is $680 \mathrm{~m}$. The relevant parameters of the $8^{\#}$ coal seam are listed in Table 1.

\section{Field measurement methods}




\subsection{Gas pressure measurement}

This study adopts the APM method to measure the coal seam gas pressure. All the measurement holes are downward to the PDCS (Fig.3). The cement slurry seals the hole and prevents the leakage of gas during the tests, thus ensuring the accuracy of the measurements. The arrangement of the test boreholes and sealing method are shown in Fig.3. The process for the measurement are as follows: pipe laying $\rightarrow$ grouting and sealing $\rightarrow$ sealing the top orifice $\rightarrow$ checking the gas flow path $\rightarrow$ installing the pressure gauge $\rightarrow$ observing the gas pressure. The specific operation for each step includes: (1) Using galvanized iron pipe with pressure measuring kit (measure gas pressure), and choosing a pressure gauge with appropriate range according to the estimated pressure. (2) Pouring sodium silicate into the hole and sealing the hole with expanded cement at the same time. (3) The prepared expansive cement slurry is rapidly injected into the borehole and stopped at the location of $0.5 \mathrm{~m}$ to the top orifice. (4) Connecting the iron pipe with the pressure air pipe, slowly opening the pressure air, and observing whether there is airflow from the gas outlet of the pressure kit. (5) Installing pressure gauge after cement slurry has solidified for 24 hours. (6) Regularly observing the gas pressure until it does not change.

\subsection{Gas content measurement}

The HPA method with direct gas content (DGC) meter is used to measure the coal seam gas content (Pan et al., 2019). The gas content is mainly measured by underground coring, underground desorption, coal sample weighing and crushing, moisture measurement, and other methods. After drilling into the coal seam, the drill bit is withdrawn, and the coring bit is replaced. The obtained coal sample is loaded a tank immediately and sealed. Sample desorption is carried out in the site, and the data is recorded. Finally, the sealed coal sample tank is brought to the laboratory for further desorption to obtain the accurate gas content.

\subsection{Permeability coefficient measurement}

The permeability coefficient is usually used to describe the fluidity of the gas flow in the coal seam. Over the past few decades, various methods have been proposed to measure and calculate the permeability coefficient. These methods can be divided into two categories: (a) laboratory measurement methods and (b) in-situ measurement methods. Due to the heterogeneity (i.e., stress and physical parameters) of the coal mass, laboratory tests cannot fully reflect the reality of the field environment. Generally, there are four methods for field measurements of coalbed gas permeability: (a) Radial flow permeability method; (b) Krichevsky gas pressure method; (c) Marconi gas pressure method; (d) Krichevsky gas flow quantity method. RFP is widely used in Chinese coal mines (Liu et al. 2020; Zhou, 1984), which is also employed in this study. The basic assumptions of this method contain: (1) The roof and floor of the coal seam are impervious rock layers and do not contain gas; (2) The permeability and porosity of the coal seam are not affected by the change of gas 
125

pressure; (3) There is little change in temperature in the flow field, and the gas flow is isothermal; (4) Methane behaves as an ideal gas with laminar permeation, i.e., Darcy flow, as shown in Fig. 4. The differential equation of the radial unsteady flow of a borehole can be given

$$
\frac{\partial P}{d t}=\frac{4 \lambda P^{-0.75}}{\alpha}\left(\frac{\partial^{2} P}{\partial r^{2}}+\frac{1}{r} \cdot \frac{\partial P}{\partial r}\right)
$$

where $r$ is the radius to the borehole, $\mathrm{m} ; P$ is the square of the gas pressure in the coal seam, $\mathrm{MPa}^{2} ; \alpha$ is the gas content coefficient, $\mathrm{m}^{3} /\left(\mathrm{m}^{3} \cdot \mathrm{MPa}^{1 / 2}\right) ; t$ is the time of gas flow, $\mathrm{d} ; \lambda$ is the permeability coefficient of the coal seam, $\mathrm{m}^{2} /\left(\mathrm{MPa}^{2} \cdot \mathrm{d}\right)$, it can also be calculated

$$
\lambda=\frac{k}{2 \mu p_{n}}
$$

where $p_{\mathrm{n}}$ is the atmospheric pressure in the site, $\mathrm{MPa} ; \mu$ is the dynamic viscosity of methane, $\mathrm{Pa} \mathrm{s} ; k$ is the permeability, $\mathrm{m}^{2}$. After Laplace transform and combined with the similarity theory, $\lambda$ can be determined using the following to equations

$$
\begin{gathered}
Y=a_{1} F_{0}^{b_{1}} \\
Y=\frac{q r_{1}}{\lambda\left(p_{0}^{2}-p_{1}^{2}\right)} \\
F_{0}=\frac{4 t p_{0}^{1.5}}{\alpha r_{1}^{2}}
\end{gathered}
$$

where $Y$ is dimensionless flow criterion; $F_{0}$ is dimensionless time criterion; $a_{1}$ and $b_{1}$ are regression coefficient; $p_{0}$ is the initial gas pressure in the coal seam, $\mathrm{MPa} ; p_{1}$ is the gas pressure in the borehole, MPa; $r_{1}$ is the radius of the borehole, $\mathrm{m}$; $q$ is the gas flow rate per area of borehole wall at the time $t, \mathrm{~m}^{3} /\left(\mathrm{m}^{2} \cdot \mathrm{d}\right)$, i.e.,

$$
q=\frac{Q}{2 \pi r_{1} L}
$$

where $Q$ is the gas flow rate of the borehole when the discharge time is $\mathrm{t}, \mathrm{m}^{3} / \mathrm{d} ; L$ is the length of the borehole in the coal seam, generally taken as the seam thickness, m. Let

$$
\begin{gathered}
A=\frac{q r_{1}}{p_{0}^{2}-p_{1}^{2}} \\
B=\frac{4 t p_{0}^{1.5}}{\alpha r_{1}^{2}}
\end{gathered}
$$

The formulas for calculating the permeability coefficient by the RFP method are listed in Table 3 . When calculating the permeability coefficient, any formula in Table 2 can be used to obtain an assessed value first, then the results are checked by $F_{0}=B \lambda$. If the value of $F_{0}$ is in the range of the selected formula, the result is correct. Otherwise, another formula can be used, until the value of $F_{0}$ is in the range of the selected formula.

The steps to calculate the permeability coefficient are as follows: (1) a borehole through the coal seam is drilled, then seal the borehole and measure the initial gas pressure. (2) then open the valve and reduce the pressure in the borehole to 
153

154

155

156

157

158

159

160

161

162

163

164

165

166

167

168

169

170

171

172

173

174

175

176

177

178

179

180

181

the atmospheric pressure. (3) Measure the natural gas emission from the borehole two hours at a time, twice a day, and then calculate the permeability coefficient according to formulas in Table 2. Permeability coefficient tests are performed after the gas pressure measurement at the same test borehole, as shown in Fig. 3. Because of the damage near the borehole, the gas flow rate usually indicates a high value with strong fluctuations during the first few hours. However, it rapidly reduces and remains constant after one day. Field operations in this study suggest that the gas flow rate is more reliable two days after the drilling.

\subsection{Test drilling holes layout}

The dip angle of coal seams is $10 \sim 20^{\circ}$. According to the provisions for the prevention of coal and gas outburst (Wang et al., 2013), the theoretical tendency and strike pressure-relief angle of the upper PCS mining is $75^{\circ}$ and $56^{\circ}$, respectively. Therefore, locations of the test drill holes for gas pressure, content, and permeability coefficient should be around the theoretical pressure relief boundary (TPRBL), as shown in Fig. 5. Five groups (A, B, C, D, E) of test drills and their locations were theoretically designed and are shown in Figs. 6 and 7, respectively.

(1) Test holes at the PCS2 tailgate-1 (Group A)

Holes were drilled into the PDCS longwall face in the tailgate-1 of the PCS2 longwall face before the PCS longwall face retreated. The PDCS longwall face will be mined after the PCS longwall face. The gas pressure of the PDCS longwall face was measured as the PCS longwall face advances. There were four test points along the strike and tendency of the PDCS longwall face, respectively, as seen in Fig. 6A. By testing the residual gas pressure in the $1^{\#}, 5^{\#}$, $6^{\#}, 7^{\#}$, and $8^{\#}$ holes, it is possible to examine the pressure-relief effectiveness of the $8^{\#}$ coal seam before and after mining of the PCS longwall face. The test holes in the tailgate-1 of the PCS2 longwall face were failed, so measurements are not available in these holes.

(2) Test holes at the PCS2 tailgate-2 (Group B)

Due to the ventilation requirements, the tailgate- 2 was constructed on the PCS2 longwall face, as shown in Fig. 5. There are four test holes in the tailgate- 2 to observe the change in gas pressure and permeability coefficient in the PDCS panel during the PCS longwall retreating. The layout of the drilled holes is shown in Fig. 6B. As can be seen in Figs. 5 and $6 \mathrm{~B}$, the $2^{\#}$ drill hole is located outside the pressure-relief scope at a distance of $12 \mathrm{~m}$ from the TPRBL; the $3^{\#}$ drill hole is near the TPRBL at a distance of $2 \mathrm{~m}$ to the boundary; the $4^{\#}$ drilling hole is located within the TPRBL at a distance of $8 \mathrm{~m}$ to the boundary.

(3) Test holes at the PDCS main roadway (Group C)

After finishing the PCS panel, three test holes were drilled in the main roadway in the PDCS mining area. As seen in Fig. 5, the $3^{\#}$ drilling hole was located within $10 \mathrm{~m}$ of the TPRBL, the $2^{\#}$ drilling hole was located within $1 \mathrm{~m}$ of the TPRBL, and the $1^{\#}$ drilling hole was located $14 \mathrm{~m}$ outside the TPRBL. Figure 6C shows the sectional view of the 
drilling holes. Because of the faults in this area, coal samples were not obtained during the construction of the $3^{\#}$ drilling hole. The other two drilling holes were constructed according to the design angle. The measured gas content of the $1 \#$ and $2 \#$ holes is 8.71 and $5.39 \mathrm{~m}^{3} / \mathrm{t}$, respectively. The gas content of the $2^{\#}$ drilling holes decreased by $62.96 \%$. However, there is no pressure-relief in the $1 \#$ holes.

(4) Test holes at the PDCS headgate cross-cut (Group D)

Six test holes were designed at the headgate cross-cuts to measure the residual gas pressure in the PDCS and inspect the strike and tendency pressure-relief angles of the PCS longwall face. In Fig. 5, the 1\# 3\# drilling holes were used to test the strike pressure-relief angle and Fig. $6 \mathrm{D}$ shows the profile of the arrangement. The $1 \#$ hole was located within $10 \mathrm{~m}$ to the TPRBL; the 2\# drilling hole was located on the TPRBL; and the 3\# drilling hole was located $10 \mathrm{~m}$ outside the TPRBL. The $4 \# \sim 6 \#$ holes were used to determine the tendency pressure-relief angle. The $4 \#$ hole was located within 10 $\mathrm{m}$ to the TPRBL; the 5\# hole was located on the TPRBL; and the $6 \#$ drilling hole was located $10 \mathrm{~m}$ outside the TPRBL. As the $4 \# \sim 6 \#$ holes were close to the PCS headgate, fractures around the holes developed. After the holes were sealed, a leakage occurred in the roadway; thus, the gas pressure and permeability coefficient measurements were not available. Therefore, only the gas pressure measurements in the $1 \# \sim 3 \#$ drilling holes were implemented. The coal sample collection was executed in the $1 \# \sim 6 \#$ holes, and the samples were used to test the coal seam gas content. The corresponding results are shown in Table 3 . The gas pressure of the $1 \# \sim 3 \#$ drilling holes is shown in Fig. 7 . It clearly shows the gas pressure gradually increases but is still lower than the original gas pressure in the coal seams, indicating that there is also a certain pressure-relief beyond the TPRBL. Moreover, the further inside the TPRBL, the higher the pressure-relief.

(5) Test holes at the PDCS tailgate cross-cut (Group E)

Three test holes were arranged in the PDCS tailgate cross-cut. The section and planar graphs of the arrangement are shown in Fig. 5 . The $1 \#$ hole was located $10 \mathrm{~m}$ beyond the TPRBL; the $2 \#$ hole was located on the TPRBL; and the $3 \#$ hole was located within $20 \mathrm{~m}$ of the TPRBL. The gas content and permeability coefficient are listed in Table 3 . The gas content from the $2 \#$ and $3 \#$ holes decreases to $61.09 \%$ and $54.78 \%$ of their original values, respectively.

\section{Field test results}

\subsection{Gas pressure evolutions}

Fig. 8 shows the development of the gas pressure at each test hole of group B with the advancement of the PCS longwall face. The gas pressure gradually decreases when the PCS longwall face passes the monitoring point. The gas pressure at the $4 \#$ hole within the pressure-relief range has the greatest reduction; the gas pressure at the $3 \#$ hole located on the pressure-relief line also drops, indicating that the PDCS located around the $3 \#$ monitoring point also experienced pressure-relief but with a lower reducing rate of $34.2 \%$. The result also demonstrates that the tendency pressure-relief 
scope is larger than that of the theoretical one, but the $3 \#$ hole only underwent partial pressure-relief comparing with the 4\# monitoring hole. The gas pressure at the $2 \#$ monitoring point is unchanged, indicating that the pressure-relief effect is limited. Gas pressure measurement in the $1 \#$ hole failed, so the data is not available.

The gas pressure evolution showing in Fig. 8 indicates the strike pressure relief angle is smaller than the theoretical value. The gas pressure decreased rapidly $2.5 \mathrm{~m}$ behind the theoretical pressure relief line, and then remained constant until $7.5 \mathrm{~m}$ behind the theoretical pressure relief line. Therefore, it concludes the measured pressure relief boundary should be $2.5 \mathrm{~m}$ smaller than the theoretical one, and the corresponding strike pressure relief angle is $52.2^{\circ}$. Most of the pressure-relief gas will flow into the PCS longwall face through the floor fractures, which affects the safety of PCS mining (Zhang et al., 2016). Therefore, gas drainage using floor drillings is recommended to extract the pressure-relief gas during the PCS longwall face retreating. It is helpful to reduce the gas pressure in the pressure relief range, as well as to expand the pressure relief range in the PDCS.

\subsection{Permeability coefficient evolutions}

Permeability coefficient is monitored in the $2 \#, 3 \#$, and $4 \#$ holes in group B after gas pressure measurements. The monitored results during the PCS retreating are shown in Fig. 9. The mining of the PCS causes a significant increase in the permeability of the PDCS. The permeability evolution in each monitoring holes can be divided into four stages: slowly decreasing, sharply increasing, gradually decreasing, and basically stable. Taking the monitoring data of $4 \#$ borehole as an example, the permeability of the PDCS remains if the monitoring location is beyond the effect of the PCS longwall mining, i.e., more than $30 \mathrm{~m}$ away from the longwall face. The permeability slowly decreases when the boreholes in the range of $-30 \mathrm{~m}$ and $10 \mathrm{~m}$ in relation to the longwall face. It then increases sharply with a distance of 10 $\mathrm{m}$ to $30 \mathrm{~m}$ behind the longwall face. After that, the permeability dramatically reduces until the monitoring holes are approximately $70 \mathrm{~m}$ behind the longwall face. Finally, the permeability gradually stabilizes. The permeability evolution attribute to the stress change of the PDCS during the PCS mining, as shown in Fig. 10. The PDCS can be divided into five zones during mining of the PCS: the in-situ stress zone, the abutment stress influence zone, the pressure-relief zone, the gradually compacted zone, and the compacted stable zone. In the in-situ stress zone, the mining of the PCS does not affect the PDCS, and the permeability unchanged. In the abutment stress influence zone, the stress increase causes the permeability to decrease gradually. While in the pressure relief zone, a large number of expansion fractures are created, significantly increasing the permeability. In the gradually compacted zone, the permeability gradually decreases as the goaf compacts. When the goaf is fully compacted, the permeability of the PDCS remains constant.

In Fig 9, it can be seen that the permeability has relative quick increases in the pressure relief zone ( $\sim 20 \mathrm{~m}$ in length) and the gradually compacted zone ( $40 \mathrm{~m}$ in length). The maximum permeability coefficient is $2.58 \mathrm{~m}^{2} /\left(\mathrm{MPa}^{2} \cdot \mathrm{d}\right)$, 
which was about 322 times the original permeability $\left(0.008 \mathrm{~m}^{2} /\left(\mathrm{MPa}^{2} \cdot \mathrm{d}\right)\right)$; therefore, it is the best choice for gas extraction within this area. In the compacted stable zone, due to the created fractures (Zhang et al., 2018), the permeability coefficient still stays at a high level even if the stress recoveries to the in-situ state (Bai et al., 2017). It clearly shows the permeability coefficient usually increased by 100 times due to the PCS mining.

The evolution of gas extraction rate and concentration in the PDCS during PCS advancing are shown in Fig.11. When the monitoring holes were $15 \mathrm{~m}$ behind the PCS longwall face, the gas extraction rate and concentration begin to increase significantly. The two arguments maximize at the location about $30 \mathrm{~m}$ behind the longwall faces, and then gradually declines to constant values. The evolution of two arguments further verifies the permeability measurements, showing the zonal characteristics and pressure relief dependency. It should be noted that the decrease in gas extraction rate is not only related to the permeability decrease but also resulted from the reduction in gas pressure (Zhang et al., 2015b).

To study the pressure relief scope, the evolution of permeability coefficient in $3 \#$ and $2 \#$ boreholes located outside of $4 \#$ borehole is also given in Fig. 9. The permeability coefficient at the $3 \#$ monitoring point (located on the pressure-relief line) also increases, indicating the PDCS also has a pressure-relief effect near the pressure-relief boundaries with the maximum permeability coefficient of $0.3 \mathrm{~m}^{2} /\left(\mathrm{MPa}^{2} \cdot \mathrm{d}\right)$. While outside of the pressure-relief range, the pressure-relief effect is limited. For example, the maximum permeability coefficient of 2 \# borehole reached $0.102 \mathrm{~m}^{2} /\left(\mathrm{MPa}^{2} \cdot \mathrm{d}\right)(12.75$ times the original value); however, the permeability coefficient quickly decreases to a low level due to the short time of the pressure relief effect.

\section{Determination of the pressure relief angles and gas outburst control area}

Because the monitoring boreholes in groups $\mathrm{C}, \mathrm{D}$, and $\mathrm{E}$ are close to the installation roadway, it is difficult to monitor the evolution of gas pressure and permeability during the panel retreating. Moreover, continuous monitoring is relatively complicated and high cost. Therefore, continuous monitoring was only carried out in group B boreholes. The residual gas content, pressure, and permeability coefficient of the PDCS were measured after the PCS longwall panel finished.

In the process of drilling, some boreholes only took out the coal samples, but the gas pressure was not measured. Besides, since the coal sample needs to be taken out during the gas content measurement, the same borehole can only be measured once. For continuous monitoring, the borehole in group B has been drilled before PCS mining; thus, the measurement of residual gas content cannot be implemented. According to the results of the gas pressure or gas content test, and considering the adsorption constant of $8 \#$ coal seam (see Table 1), the gas content or gas pressure in each hole can be calculated by Eq. (9) (Zhang et al., 2017). 


$$
W_{C Y}=\frac{a b\left(P_{C Y}+0.1\right)}{1+b\left(P_{C Y}+0.1\right)} \times \frac{100-A_{a d}-M_{a d}}{100} \times \frac{1}{1+0.31 M_{a d}}+\frac{\pi\left(P_{C Y}+0.1\right)}{\gamma P_{a}}
$$

where $W_{\mathrm{CY}}$ is the residual gas content $\left(\mathrm{m}^{3} / \mathrm{t}\right) ; P_{\mathrm{CY}}$ is the residual gas pressure (MPa); $a$ and $b$ are adsorption constants ( $\mathrm{mL} / \mathrm{g}$ and $\mathrm{MPa}^{-1}$, respectively); $\pi$ is the coal porosity. The calculated gas content in group $\mathrm{E}$ is $8.27,5.60$, and $4.82 \mathrm{~m}^{3} / \mathrm{t}$, respectively. The errors compared with the measured data were $3.7 \%, 7.1 \%$, and $2.8 \%$, respectively, indicating that Eq. (9) could provide convincing calculations. The calculated gas pressure and gas content are shown in Table 3.

\subsection{Determination of Pressure relief angle}

(1) Strike pressure-relief angle

The strike pressure-relief angle is generally divided into two sides, as shown in Fig. 12b. One side is at the active longwall face, and the other is at the installation roadway. Since the longwall face is advancing along the strike(i.e., no inclination angle), the two angles on both sides are the same. According to the evolution of gas pressure in group B boreholes, the measured strike mining pressure-relief angle during the longwall face advancing is $52.2^{\circ}$, which is smaller than the theoretical one $\left(56^{\circ}\right)$. Gas extraction is carried out on the PDCS, which can accelerate the reduction of gas pressure and content, and expand the pressure-relief scope near the installation roadway. Therefore, the permeability coefficient is used to determine the pressure-relief angle. According to the changes in the permeability coefficient monitored by group $\mathrm{C}$ and group $\mathrm{D}$, the permeability coefficient decreases gradually from inside to outside with a negative index. An extractable critical permeability coefficient of $0.1 \mathrm{~m}^{2} /\left(\mathrm{MPa}^{2} \cdot \mathrm{d}\right)$ was used as a judgment index of effective pressure relief range according to Coal Mine Safety Regulations (Zhou et al., 2016). The measured effective pressure relief range extends $2 \mathrm{~m}$ from the theoretical line (Fig.12a), and the corresponding pressure-relief angle is $59.3^{\circ}$, a little larger than the theoretical one $\left(56^{\circ}\right)$, as shown in Fig. 12b. The pressure-relief angle at the installation roadway is higher than that at the active longwall face side, which may result from the following two reasons: (1) the pressure-relief angle at the longwall face is monitored in real-time by borehole group B, which is a dynamic parameter, and lag behind the stress transfer process. However, at the installation roadway side, the angle was measured after sufficient pressure relief occurred. (2) the decrease of gas pressure also increases permeability (Zhang et al., 2018), which caused further expansion of the pressure relief range. Therefore, the strike pressure relief angle at the installation roadway is larger than the dynamic one at the longwall face side.

(2) Tendency pressure-relief angle

The tendency pressure-relief angles at each side of the longwall panel may differ due to the tendency angle $\left(15^{\circ}\right)$ of the coal seam. The boreholes in group B and group E are used to determine the tendency pressure-relief angles on each side of the panel, as shown in Fig. 13. 1\# and 2\# boreholes in group E are used to calculate the pressure-relief angle at the tailgate side. As shown in Fig. 13a, the measured pressure relief line on the headgate side coincides with the theoretical 
relief line, and the corresponding pressure-relief angle is $75^{\circ}$. In contrast, the pressure relief line on the tailgate side expands outward by $2.2 \mathrm{~m}$, and the pressure relief angle is $78.9^{\circ}$, as shown in Fig. 13b. Therefore, the upper side (tailgate side) witnesses a better pressure relief effect, which results from the higher recovery goaf stress at the bottom side (headgate side) of the panel (Bai \& Tu, 2019).

\subsection{Determination of gas outburst control area}

The above analysis determines the pressure-relief scope in the PDCS, but the coal seam in the pressure-relief zone does not mean removing the outburst danger. According to the requirements of Coal Mine Safety Regulations (Zhou et al., 2016), the gas content in the coal seam shall not be more than $6 \mathrm{~m}^{3} / \mathrm{t}$ if the caving mining method is employed. The gas pressure is estimated to be $0.40 \mathrm{MPa}$, according to Eq. (9). The distribution of the measured residual gas content and residual gas pressure in the PDCSis shown in Fig. 14 (also see Table 3).

The gas content of the PDCS in the pressure-relief area is reduced to less than $6 \mathrm{~m}^{3} / \mathrm{t}$ (minima of $4 \mathrm{~m}^{3} / \mathrm{t}$ ). The corresponding gas pressure is usually less than $0.4 \mathrm{MPa}$ (minima of $0.18 \mathrm{MPa}$ ) in the pressure-relief area . However, outside the pressure-relief area, both of the two parameters also decrease mainly due to the gas extraction during the PCS mining. With away from the PCS pressure-relief zone, the two arguments gradually increase to their original values. Therefore, field measurements show that pressure-relief mining can remove the risk of coal and gas outbursts in the PDCS. There was no gas overrun and outburst accident during the mining process of the PDCS, which further confirmed the effect of pressure relief mining

\section{Conclusions}

Pressure-relief mining is the fundamental method to remove coal and gas outbursts in deep, high-gas pressure, and low-permeability coal seams. For the safe and efficient extraction of the subsequent PDCS, the effect of pressure-relief mining and the pressure-relief area in the PDCS were evaluated by field measurements in this paper. The corresponding field measurement and calculation methods of gas pressure, gas content, and permeability coefficient are proposed. The main conclusions are as follows:

(1) The measured results show that the gas pressure of the PDCS decreases after the PCS longwall face advances a certain distance from the monitoring point due to the existence of a pressure relief angle. The gas pressure in the PDCS outside the pressure-relief range is unchanged. The tendency pressure-relief angles of the PCS mining at the active longwall face side and installation roadway side are calculated to be $52.2^{\circ}$ and $59.3^{\circ}$, respectively.

(2) The permeability coefficient evolution in the pressure-relief range of the PDCS can be divided into four stages: slowly decreasing, sharply increasing, gradually reducing, and basically stable. The corresponding four stress zones in PDCS are the abutment stress influence zone, the pressure-relief zone, the gradually compacted zone, and the compacted stable zone, respectively. 
(3) The PDCS has the best permeability enhancement in the pressure-relief zone and the gradual compaction zone, with the length of $20 \mathrm{~m}$ and $40 \mathrm{~m}$, respectively, and the maximum permeability is 322 times of the initial permeability. The final permeability coefficient in the compacted stable zone can reach 100 times of the initial permeability. The permeability in the regions located outside the pressure -relief boundary, can also be improved to a certain extent when entering the pressure-relief zone but returns to the initial value after it compacted.

(4) The tendency pressure relief angle at the lower end of the inclined longwall face is $75^{\circ}$ consistent with the theoretical pressure relief angle; the measured pressure-relief angle at the upper end of the air roadway is extended to $78.9^{\circ}$.

(5) The residual gas content and residual gas pressure of the PDCS in the pressure-relief area are reduced to less than 6 $\mathrm{m}^{3} / \mathrm{t}$ and within $0.4 \mathrm{MPa}$, respectively. These two parameters also decreased outside the pressure-relief zone, albeit not significantly. The field measurements show that pressure-relief mining can prevent coal and gas outbursts in PDCS.

Because of the high cost, delicate operation, and danger of field measurements, it is usually challenging to monitor and evaluate the effectiveness of the pressure-relief of PCS mining. Besides, field measurements are greatly affected by mining activities and always have a low success rate. Therefore, most field measurements focused on monitoring the residual gas content or gas pressure of the PDCS after the PCS mining, which cannot fully characterize the evolution of these parameters. In this paper, by using intensive boreholes, detailed and whole mining process field measurement is carried out. For the first time, the evolution law of permeability and gas pressure in the mining process is obtained. Thus, the field observations in this paper can serve as benchmark evidence for theoretical analysis and numerical simulations.

\section{Authors' contributions}

Cun Zhang and Jianhang Chen performed the parameter design, participated in the field test, and drafted the manuscript. Qingsheng Bai, Ziyu Song and Yang Luo conducted the field measurement and conceived of, designed, and coordinated the study. All authors gave their final approval for publication.

\section{Data availability statement}

Some or all data, models, or codes that support the findings of this study are available from the corresponding author upon reasonable request.

\section{Acknowledgments}

Financial support for this work was provided by the National Natural Science Foundation of China (NO. U1910206, 51874281, 51874312), the Open Fund of State Key Laboratory of Coal Resources and Safe Mining (No. SKLCRSM19KFA17) and the Yue Qi Distinguished Scholar Project, China University of Mining \& Technology, Beijing.,

\section{Conflict of interest}


368

369

The authors declared that they have no conflicts of interest in this work.

\section{References:}

Baptiste, N., \& Chapuis, R. P. (2015). What maximum permeability can be measured with a monitoring well?. Engineering Geology, 184, 111-118.

Barrash, W., Clemo, T., Fox, J. J., \& Johnson, T. C. (2006). Field, laboratory, and modeling investigation of the skin effect at wells with slotted casing, Boise Hydrogeophysical Research Site. Journal of Hydrology, 326(1-4), 181-198.

Bai, Q., \& Tu, S. (2019). A General Review on Longwall Mining-Induced Fractures in Near-Face Regions. Geofluids, $2019,3089292$.

Bai Q, Tu S, Wang F, Zhang C (2017) Field and numerical investigations of gateroad system failure induced by hard roofs in a longwall top coal caving face. International Journal of Coal Geology 173:176-199

Esterhuizen, G., \& Karacan, C. (2005). Development of numerical models to investigatepermeability changes and gas emission around longwall mining panel. Proc Alaskarocks Us Symposium on Rock Mechanics.

Esterhuizen, G., \& Karacan, C. (2007). A methodology for determining gob permeability distributions and its application to reservoir modeling of coal mine longwalls. Sme Annual Meeting, 88(1), 012037.

Koenig, R. A., \& Schraufnagel, R. A. (1987). Application of the slug test in coalbed methane testing. paper, 8743, 195-205.

Liu, Q., Chu, P., Zhu, J., Cheng, Y., Wang, D., Lu, Y. \& Wang, L. (2020). Numerical assessment of the critical factors in determining coal seam permeability based on the field data. Journal of Natural Gas Science and Engineering, 74, 103098.

Pan, W., Guo, C., Zhao, S., Li, X., \& Peng, S. (2019). Determination of appropriate sampling depth of coalbed gas content: a case study. Journal of Geophysics and Engineering, 16(2), 411-422.

Rutqvist, J., 2011. Status of the TOUGH-FLAC simulator and recent applications related to coupled fluid flow and crustal deformations. Computers \& Geosciences 37, 739-750.

Sang, S., Xu, H., Fang, L., Li, G., \& Huang, H. (2010). Stress relief coalbed methane drainage by surface vertical wells in china. International Journal of Coal Geology, 82(3-4), 196-203.

Shu, D. M., Chamberlain, J. A., Lakshmanan, C. C., \& White, N. (1995). Estimation of in-situ coal permeability and modeling of methane pre-drainage from in-seam holes. In International Symposium on Cum Workshop on Management and Control of High Gas Emissions and Outbursts in Underground Coal Mines, Wollongong, Australia (pp. 303-310). 
398

399

400

401

402

403

404

405

406

407

408

409

410

411

412

413

414

415

416

417

418

Si, G., Shi, J. Q., Durucan, S., Korre, A., Lazar, J., \& Jamnikar, S., et al. (2015). Monitoring and modelling of gas dynamics in multi-level longwall top coal caving of ultra-thick coal seams, part ii: numerical modelling. International Journal of Coal Geology, s 144-145, 58-70.

Sun, Q., Mu, Y., \& Yang, X. (2013). Study on “two-zone”height of overlying of fully-mechanized technology with high mining height at hongliu coal mine. Journal of China Coal Society, 38(S2), 283-286.

Wang, L., Cheng, Y., Ge, C., Chen, J., Li, W., Zhou, H., \& Hai-feng, W. (2013). Safety technologies for the excavation of coal and gas outburst-prone coal seams in deep shafts. International Journal of Rock Mechanics and Mining Sciences, 57, 24-33.

Wang, W. X., Sui, W. H., \& Dong, Q. G. (2014). Influence of cover stress re-establishment on the permeability evolution of the mining-induced fractures. Journal of China Coal Society, 39(6), 1031-1038(8).

Wang, Y. G., Li, H. Y., Qi, Q. X., Peng, Y. W., Li, C. R., \& Deng, Z. G. (2010). The evolution of permeability and gas extraction technology in mining coal seam. Journal of China Coal Society, 35(3).

Whittles, D. N., Lowndes, I. S., Kingman, S. W., Yates, C., \& Jobling, S. (2006). Influence of geotechnical factors on gas flow experienced in a uk longwall coal mine panel. International Journal of Rock Mechanics \& Mining Sciences, 43(3), 369-387.

Yuan L., Guo, H., Li, P., Liang, Y. P., \& Liao, B. C. (2013). Theory and technology of goaf gas drainage with large-diameter surface boreholes. Journal of China Coal Society, 38(1), 1-8.

Yuan, L., 2008. Gas distribution of the mined-out side and extraction technology of first mined key seam relief-mining in gassy multi-seams of low permeability. Journal of China Coal Society 33, 1362-1367.

Zhao, W., Wang, K., Zhang, R., Dong, H., \& An, F. (2020). Influence of combination forms of intact sub-layer and tectonically deformed sub-layer of coal on the gas drainage performance of boreholes: a numerical study. International Journal of Coal ence \& Technology, (4), 1-10.

Zhang, C., \& Zhang, L. (2019). Permeability Characteristics of Broken Coal and Rock Under Cyclic Loading and Unloading. Natural Resources Research, 28(3), 1055-1069.

Zhang, C., Liu, J., Zhao, Y., Zhang, L., Guo, J. (2019). A fluid - solid coupling method for the simulation of gas transport in porous coal and rock media. Energy Science \& Engineering, 7, 1913-1924.

Zhang, C., Tu, S., Chen, M., \& Zhang, L. (2017). Pressure-relief and methane production performance of pressure relief gas extraction technology in the longwall mining. Journal of Geophysics \& Engineering, 14(1), 77-89.

Zhang, C., Tu, S., Bai, Q., Yang, G., Zhang, L., (2015a). Evaluating pressure-relief mining performances based on surface gas venthole extraction data in longwall coal mines. Journal of Natural Gas Science and Engineering 24, 431-440. 
429 Guo, D., Lv, P., Zhao, J., \& Zhang, C. (2020). Research progress on permeability improvement mechanisms and 430 technologies of coalbed deep-hole cumulative blasting. International Journal of Coal Science \& Technology, 7(2), $431 \quad 329-336$.

432 Zhang, C., Tu, S., Yuan, Y., \& Bai, Q. (2015b). Numerical simulation of surface gas venthole extraction in pressure 433 relief mining. Journal of China Coal Society, 40(S2), 392-400.

434 Zhang, C., Tu, S., Zhang, L., Wang, F., Bai, Q., \& Tu, H. (2016). The numerical simulation of permeability rules in 435 protective seam mining. International Journal of Oil, Gas and Coal Technology, 13(3), 243-259.

436 Zhang, C., Zhang, L., Tu, S., Hao, D., \& Teng, T. (2018). Experimental and numerical study of the influence of gas 437 pressure on gas permeability in pressure relief gas drainage. Transport in Porous Media, 124(3), 995-1015.

438 Zhang, J., \& Wang, J. (2014). Similar simulation and practical research on the mining overburden roof strata 439 "three-zones" height. Journal of Mining \& Safety Engineering, 31(2): 249-254.

440 Zhou, F., Xia, T., Wang, X., Zhang, Y., Sun, Y., \& Liu, J. (2016). Recent developments in coal mine methane extraction and utilization in China: a review. Journal of Natural Gas Science and Engineering, 31, 437-458.

442 Zhou, S., 1984. Testing on the two kinds of coal seam permeability coefficient of determination methods with computer. J. China Inst. Min. Technol. 13, 38-47. 


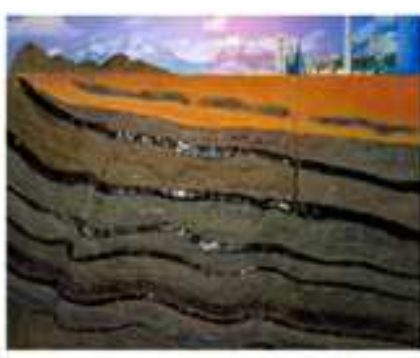

Coal reservoirs

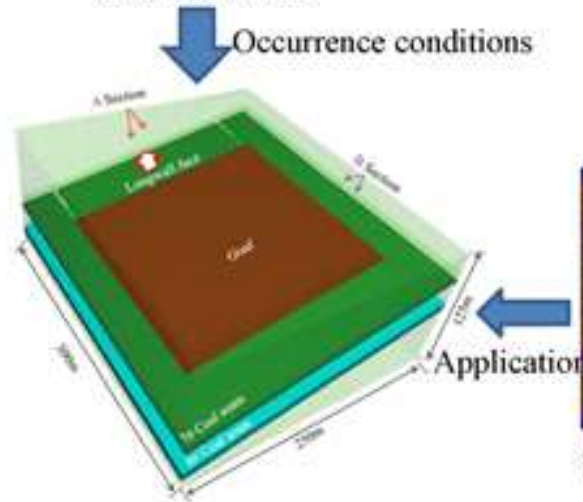

Large-scale three-dimensional model

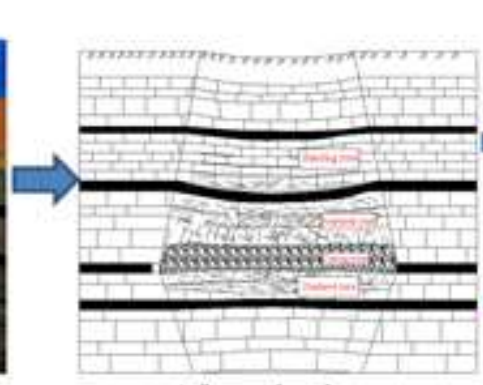

After mined

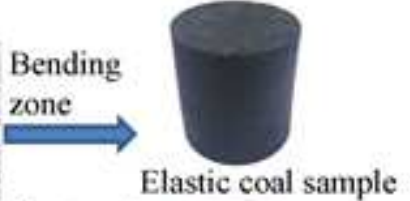

Fractured zone

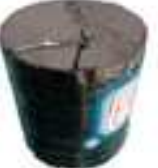

Fracture coal sample

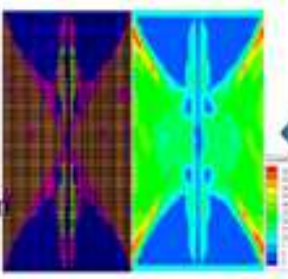

Numerical inversion

FLAC3D Laboratory permeability test
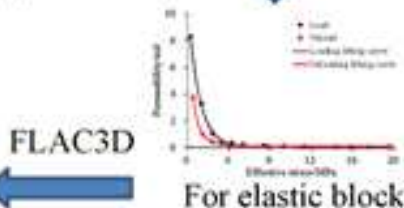

FISH

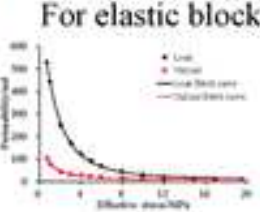

For yield block

\section{Figure 1}

A numerical method to simulate gas migration and permeability evolution in pressure-relief mining (Zhang et al., 2019)

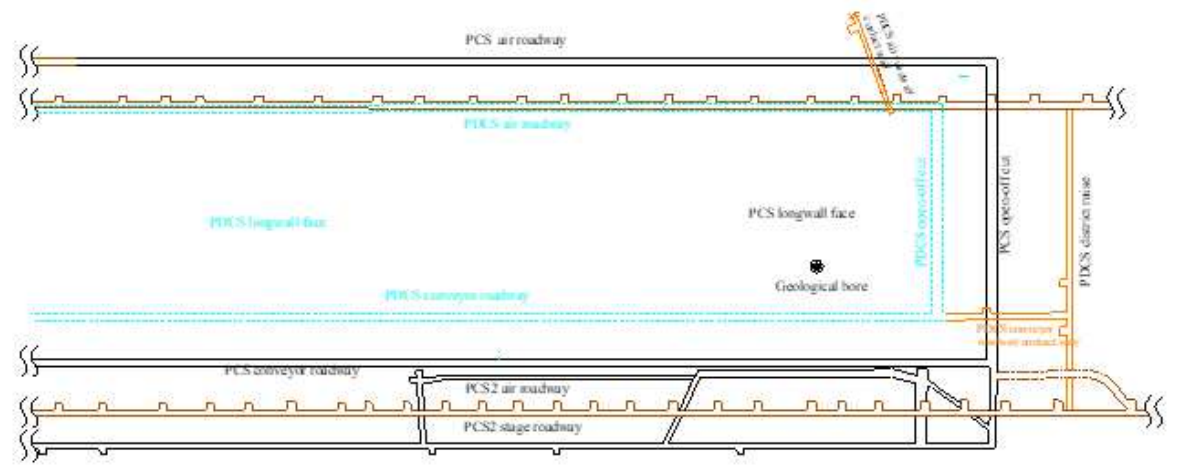

(a)

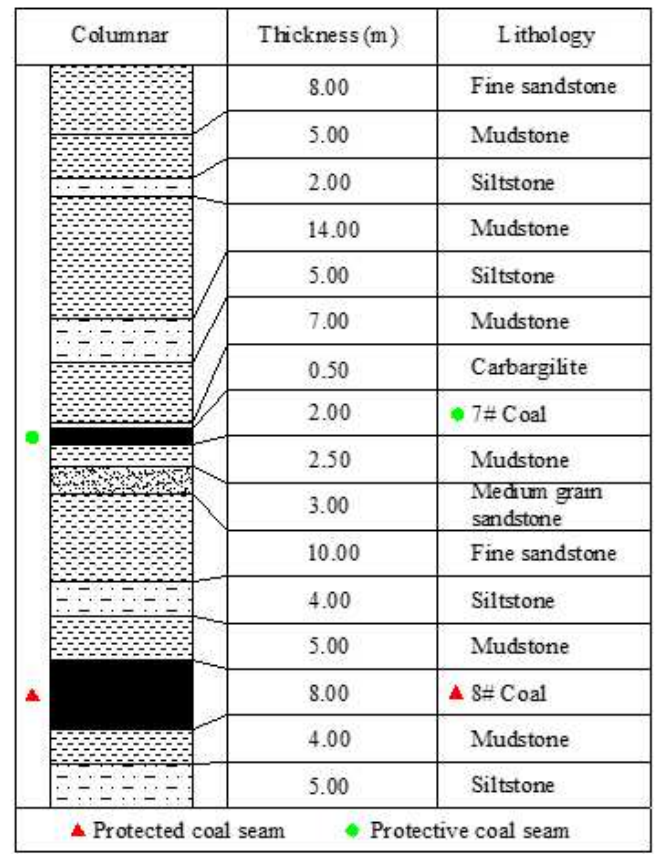

(b) 
Figure 2

2 Location of PCS and PDCS longwall face at the coal mine (a) and borehole diagram of coal measures (b)

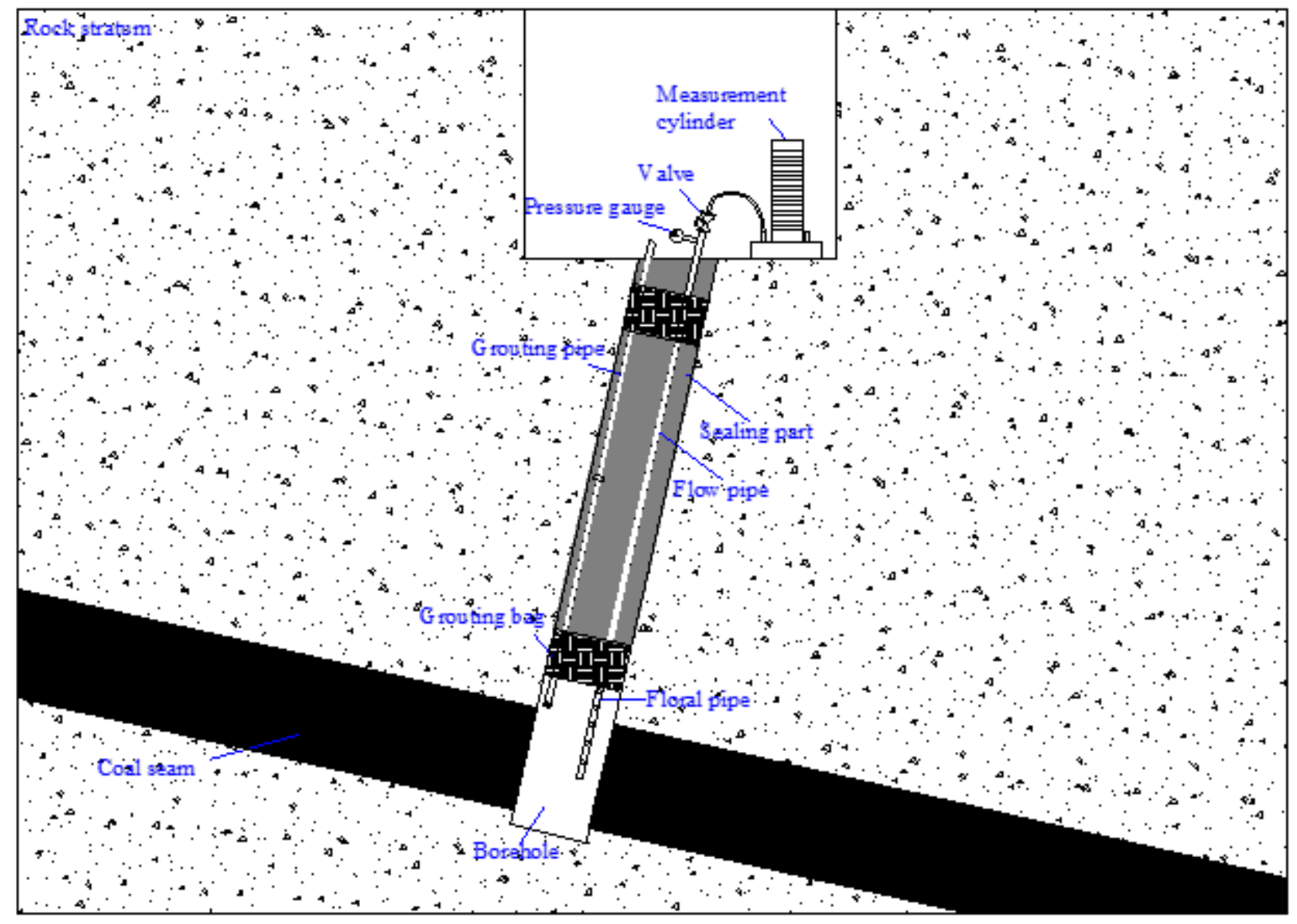

Figure 3

Diagram of field measurement of the gas pressure and the permeability coefficient

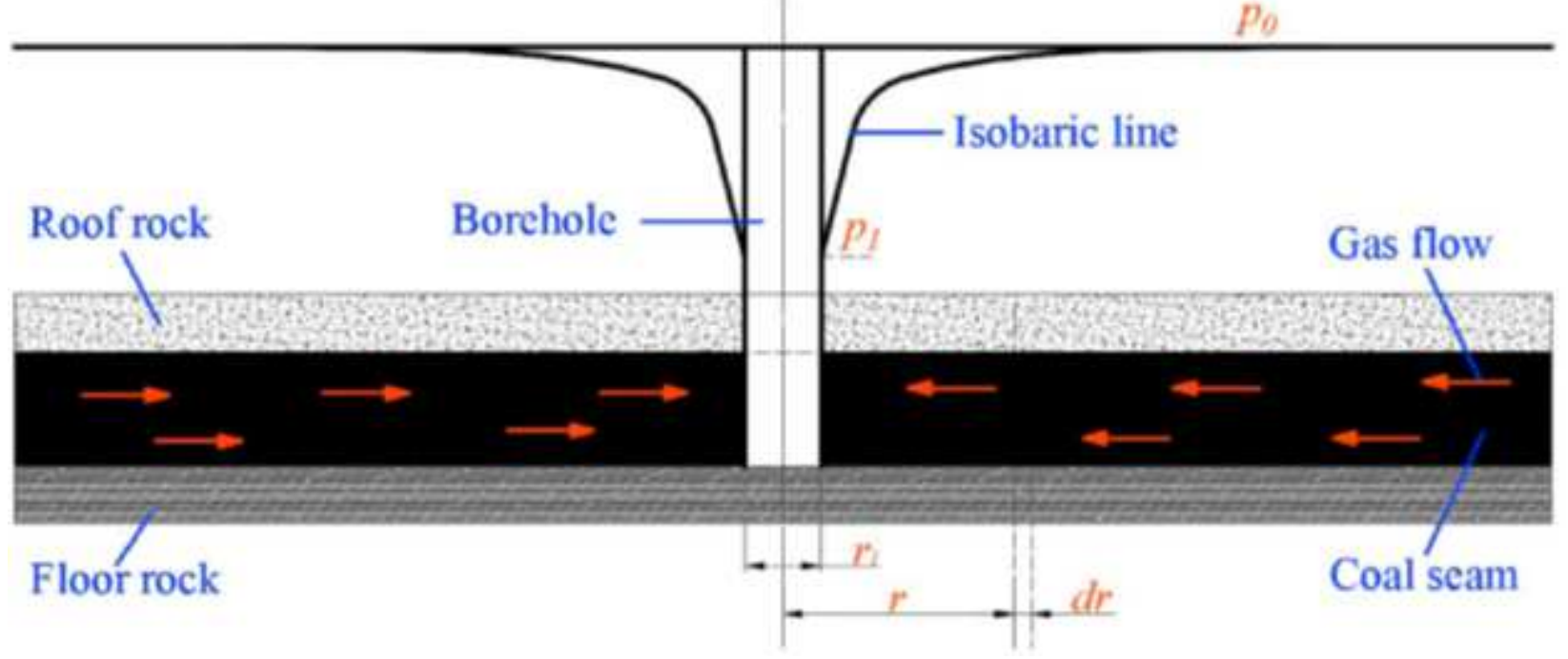

Figure 4 
Distribution of radial flow gas pressure in homogeneous coal seam (modified after Liu et al., 2020)

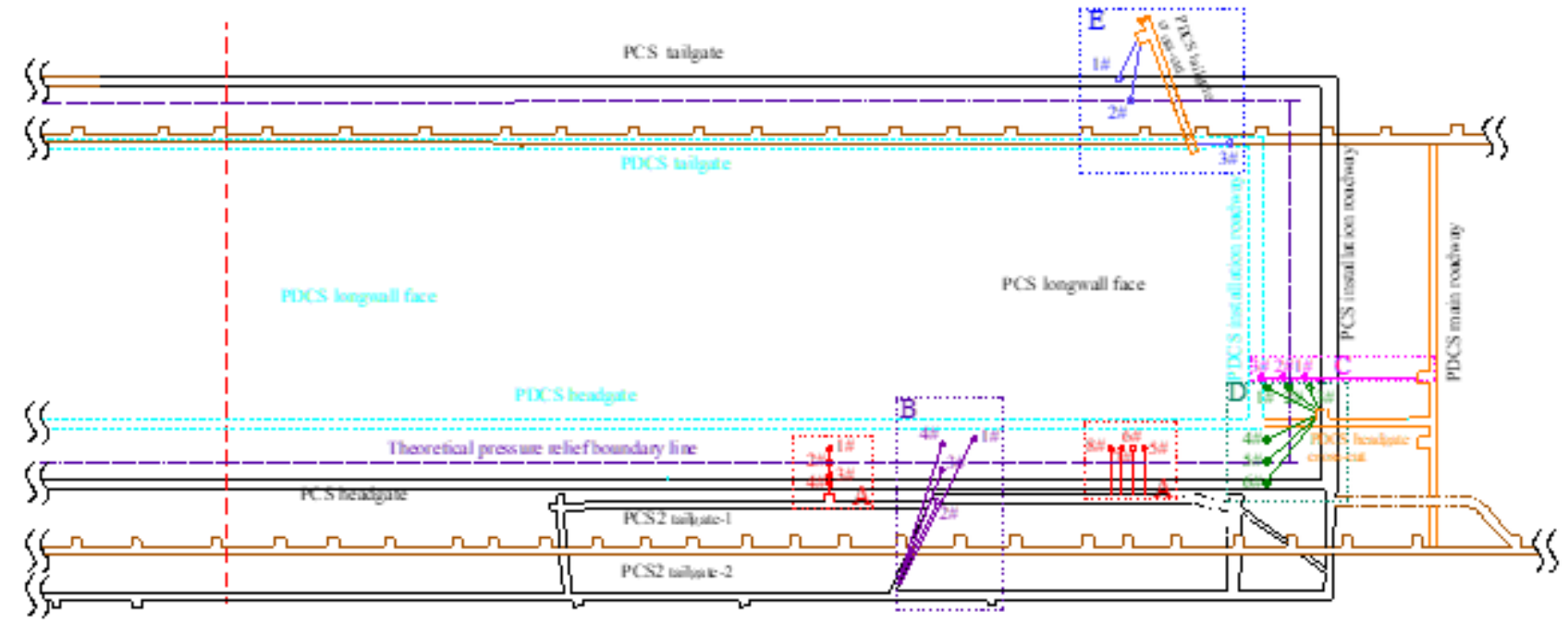

\section{Figure 5}

Layout of the test drilling holes in the protected coal seam

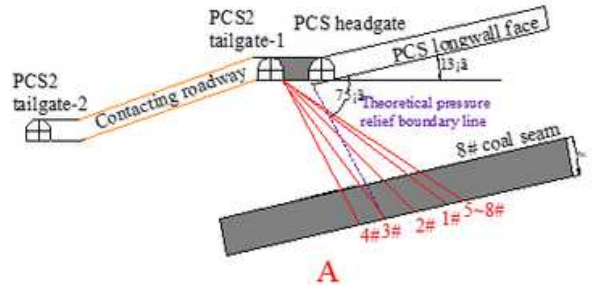

A



C

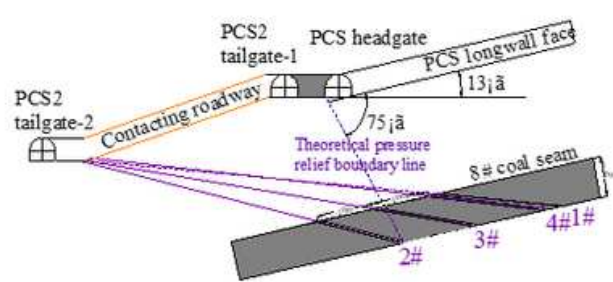

$\mathrm{B}$

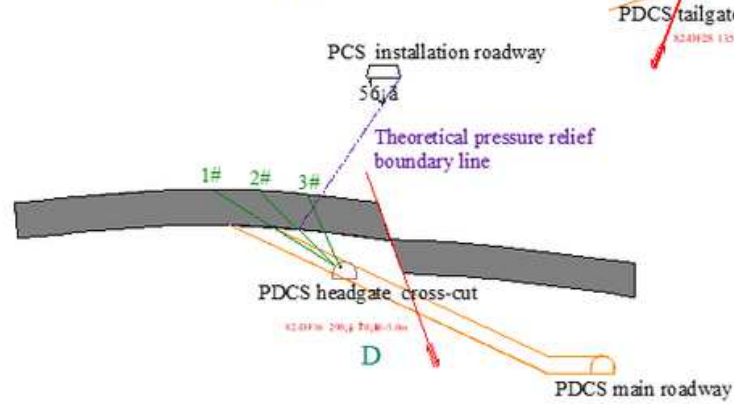

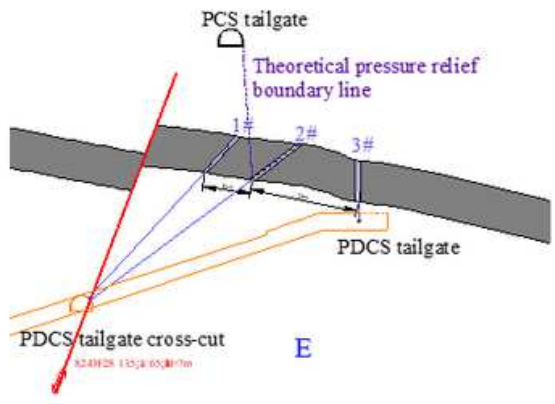

Figure 6

Design of the test drilling holes 


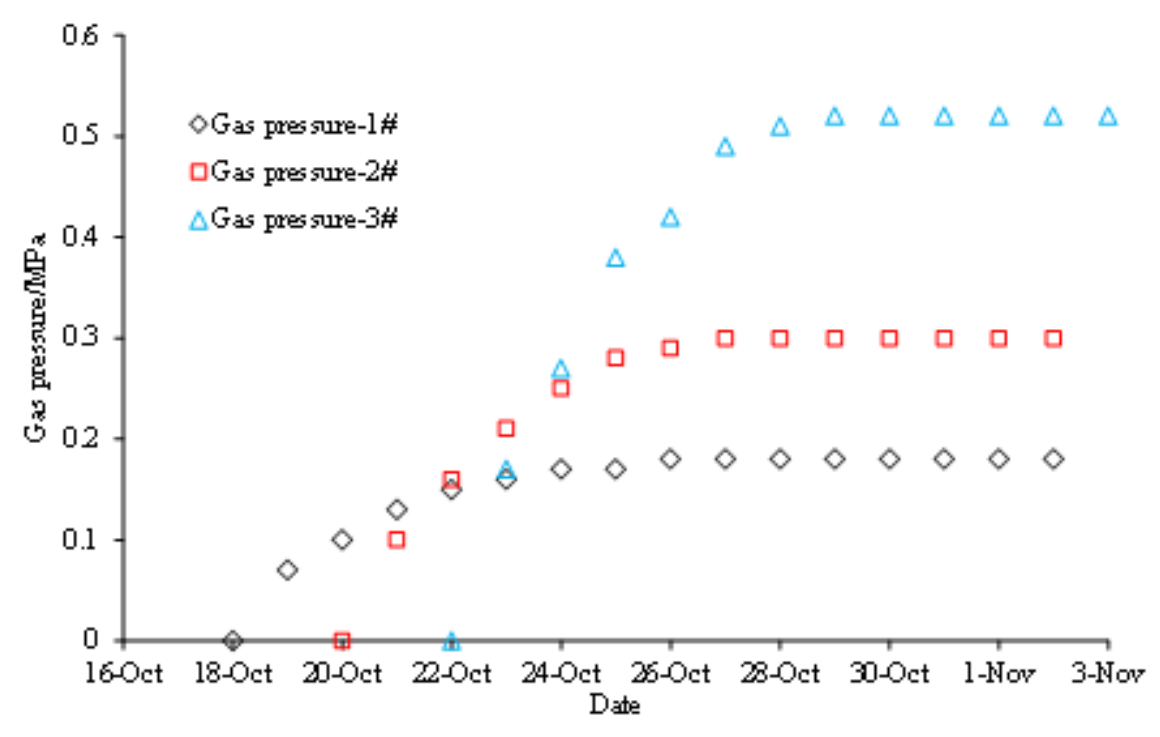

Figure 7

Gas pressure after protective coal seam mining

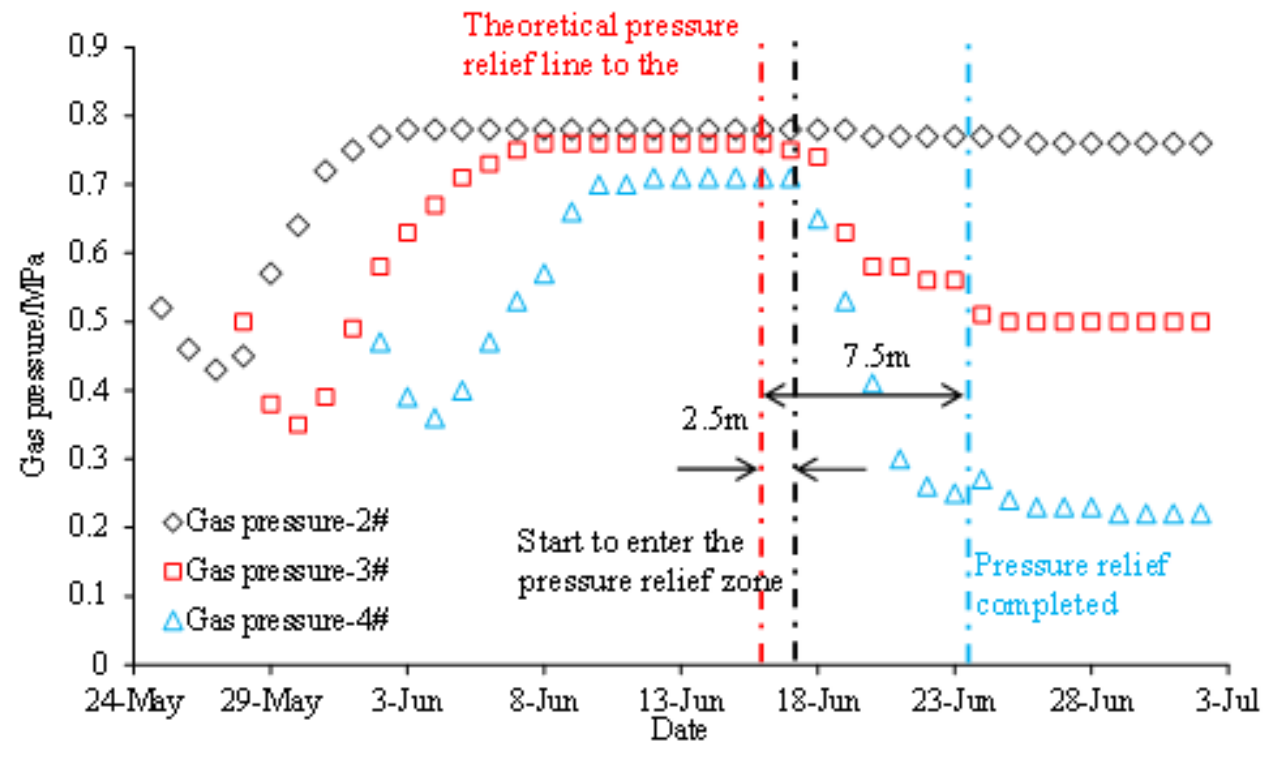

Figure 8

Gas pressure during protective coal seam mining 


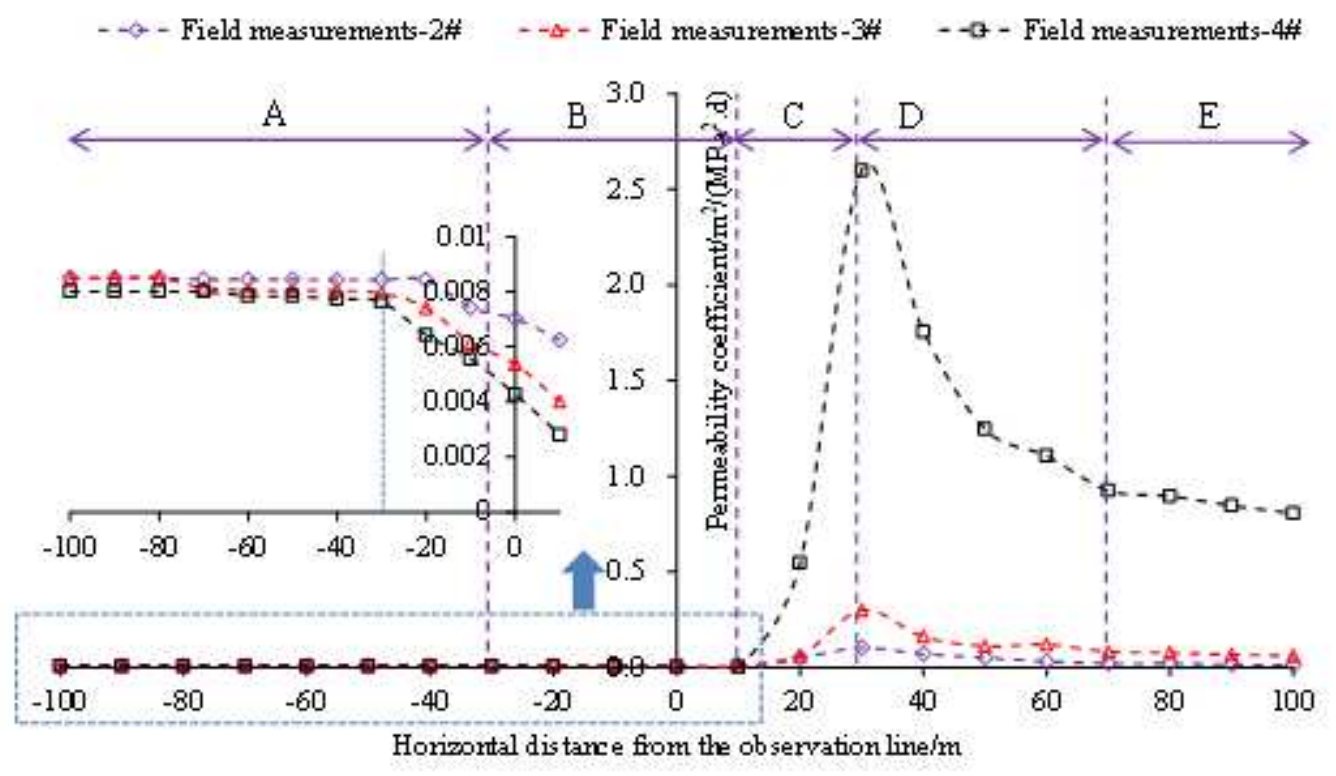

Figure 9

Permeability coefficient evolution during protective coal seam mining. A is In-situ stress zone, B is abutment stress influence zone, $\mathrm{C}$ is significant pressure-relief zone, $\mathrm{D}$ is gradually compacted zone, and $E$ is compacted stable zone. In the figure, negative and positive of the $x$-axis mean the monitoring holes are located in front of and behind the longwall face, respectively.

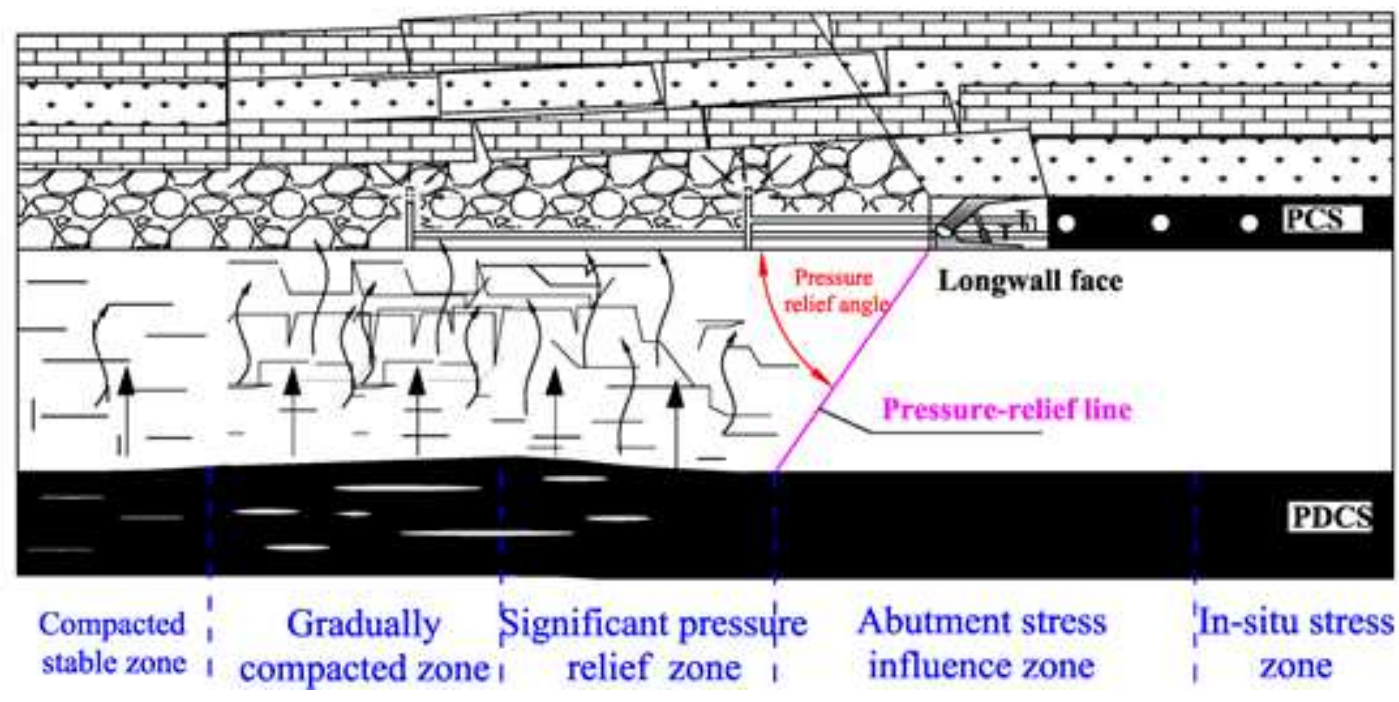

\section{Figure 10}

Schematic diagram of different pressure relief zones in PDCS during PCS mining 


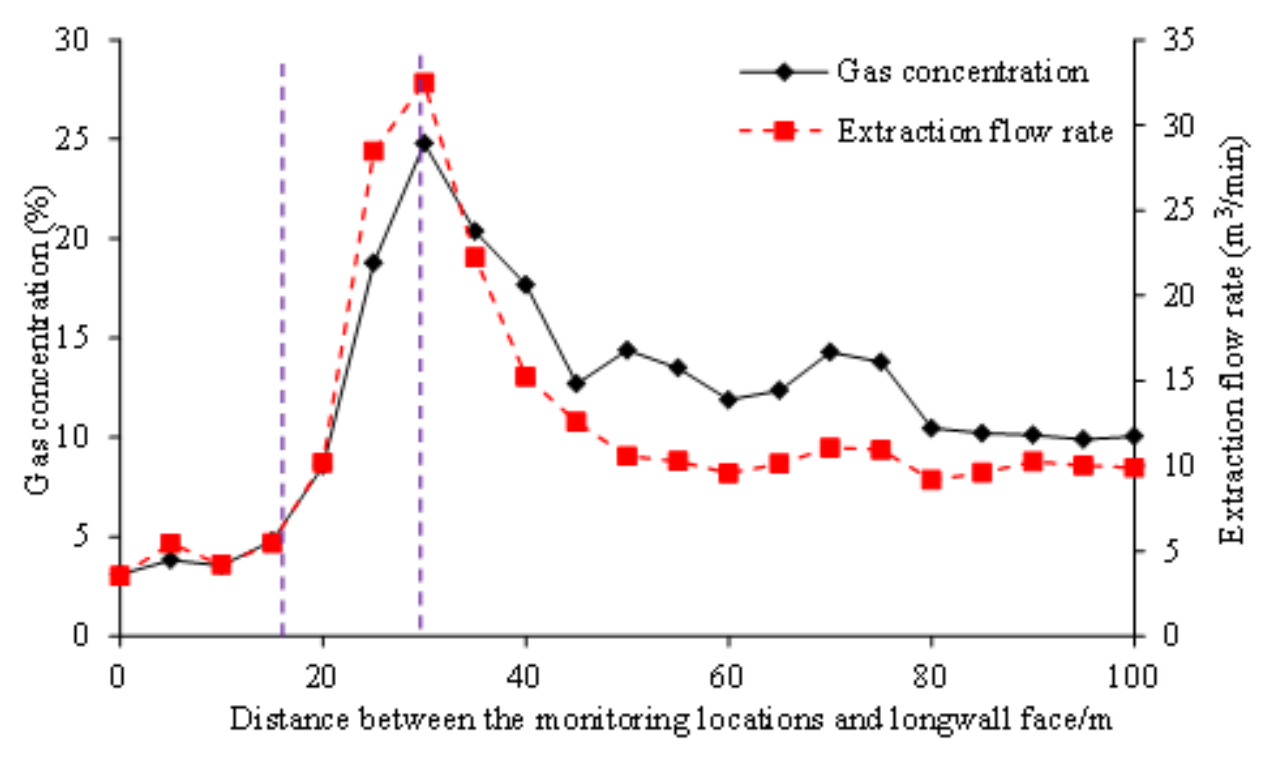

Figure 11

Gas extraction flow rate and gas concentration in the high roof roadway drainage in PDCS

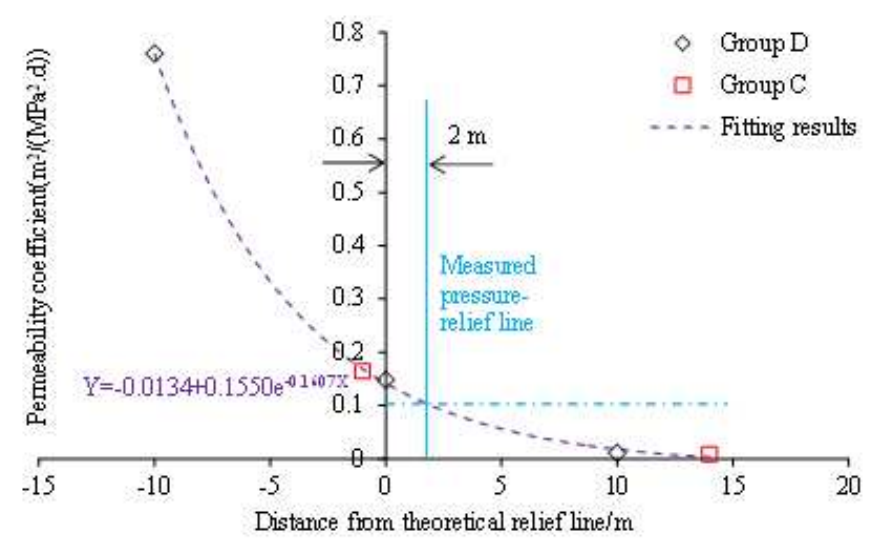

(a) Permeability coefficient distribution

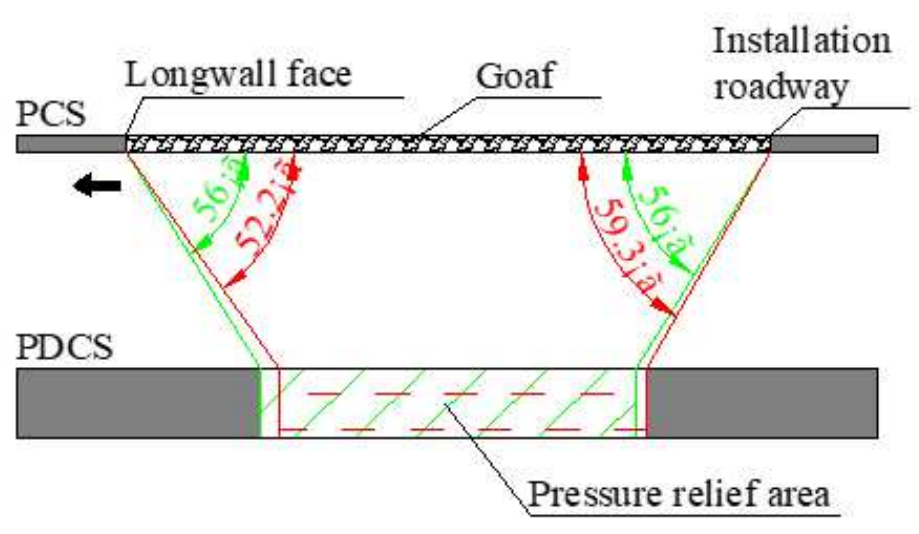

(b) Strike pressure relief angle

Figure 12

Strike pressure relief angle and its calculation 


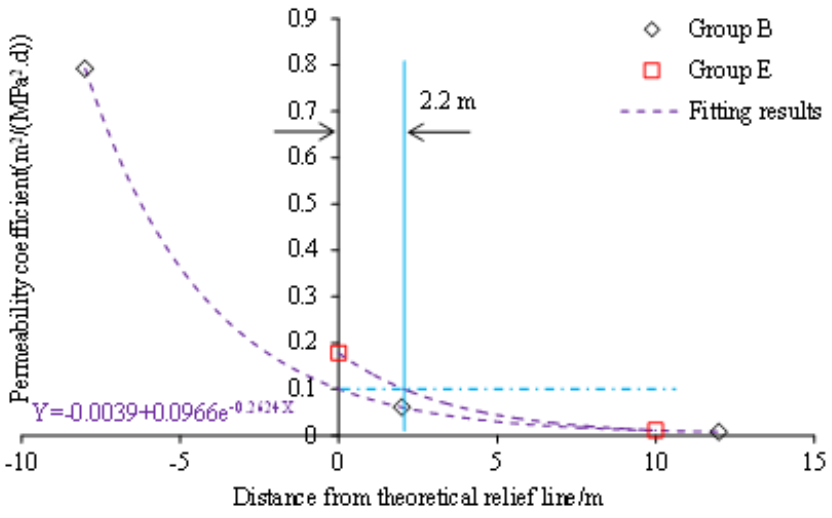

(a) Permeability coefficient distribution

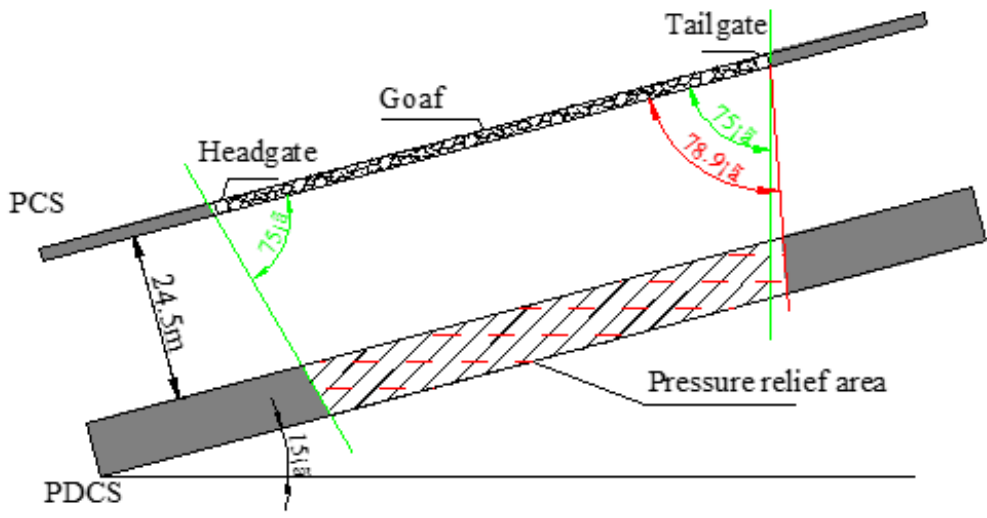

(b) Inclined pressure relief angle

\section{Figure 13}

Inclined pressure relief angle and its calculation

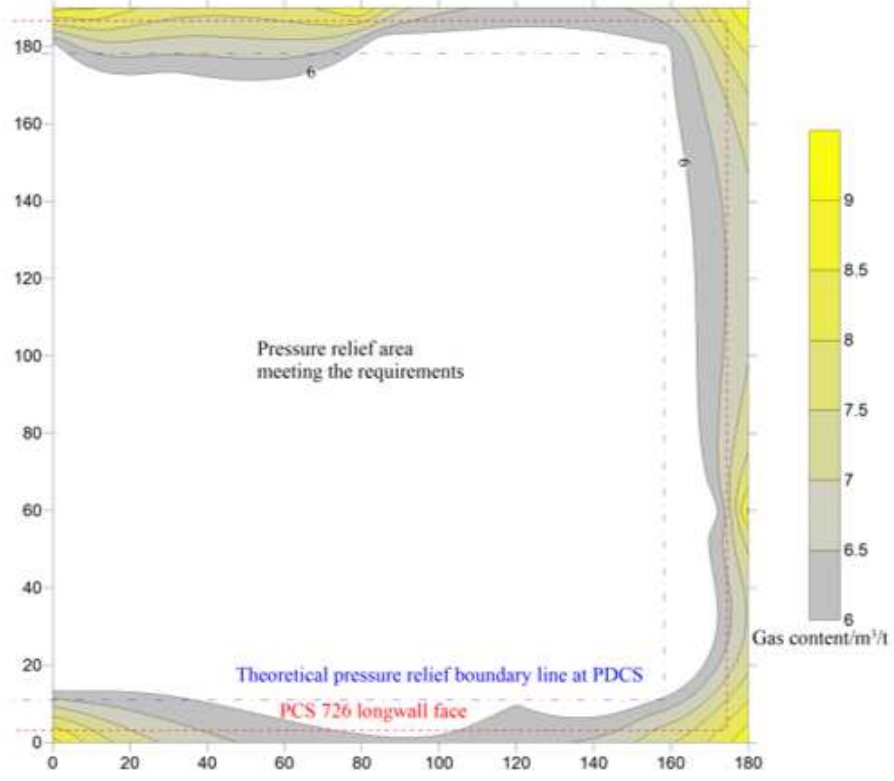

(a) Gas content

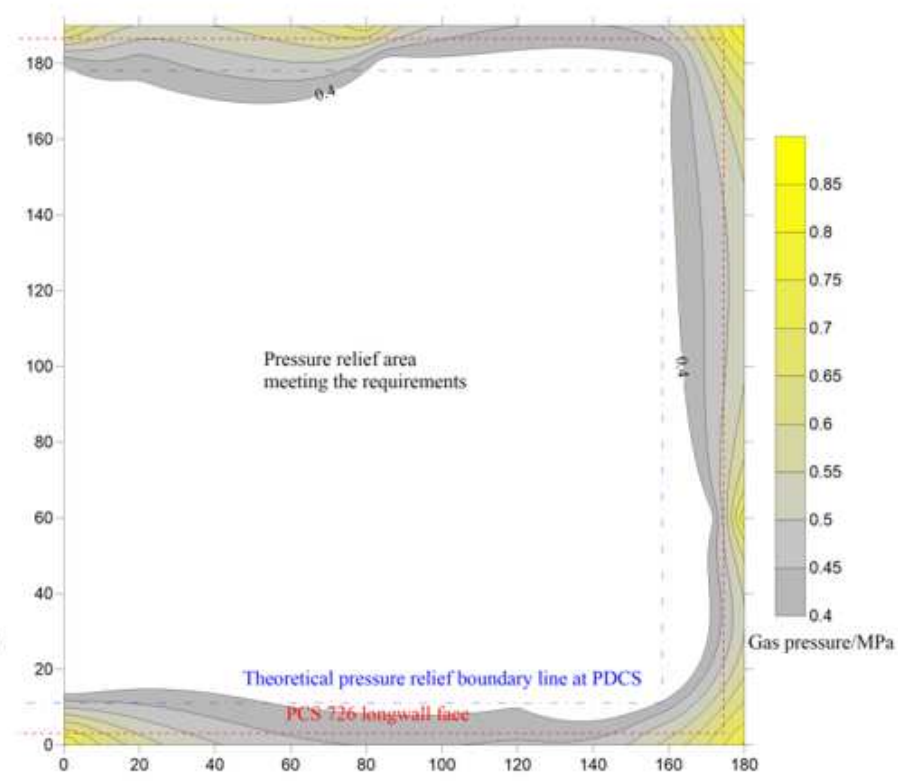

(b) Gas pressure

\section{Figure 14}

14 Distribution of the gas content (a) and residual gas pressure (b) 